\title{
Ritos e representações do paleolítico: uma leitura semiótica
}

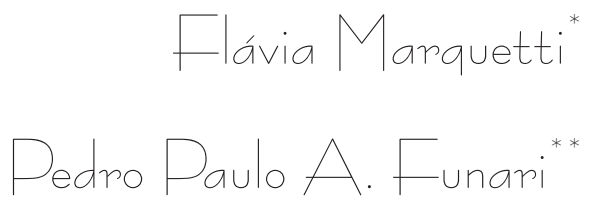

\section{Introdução: Semiótica e Pré-História}

O estudo da Pré-História apresenta desafios únicos. Só podemos ter acesso a essa Alta Antiguidade por meio de vestígios materiais, na forma de artefatos, sítios arqueológicos, restos de ossos ou plantas, pinturas parietais. Isso representa uma dificuldade, na medida em que as fontes de informação são reduzidas e pouco numerosas. Por outro lado, e de maneira na aparência paradoxal, esse fato tem a grande vantagem de tornar obrigatória a explicitação das bases epistemológicas que fundamentam o estudo da Pré-História. Não se pode partir da ilusória transparência da documentação, tentação comum quando lidamos com narrativas escritas ou orais que nos dariam a verdadeira explicação, relevariam o verdadeiro significado de rituais, atividades e crenças sociais. Claro que, mesmo nesses casos, não é possivel chegar senão a interpretações variadas e em mutação constante, pois as sociedades são complexas, com diversos interesses e grupos sociais e, além disso, as representações individuais estão sujeitas à vida interior de cada um, à psique do narrador e intérprete. Se pedirmos, hoje, que duas pessoas nos descrevam o significado da Páscoa ou de um quadro como o

\footnotetext{
* Professora doutora e pesquisadora do Grupo de Pesquisa Arqueologia Histórica - UNICAMP e LINCEU/UNESP - FCLAR. E-mail: flaviarm@fclar.unesp.br

** Professor doutor titular do Departamento de História do Instituto de Filosofia do IFCH/UNICAMP. E-mail: ppfunari@uol.com.br
} 
Grito da Independência, teremos duas narrativas diversas e, em potência, contraditórias.

No caso da Pré-História, ao não contarmos com as narrativas dos próprios atores sociais, estamos livres das armadilhas das interpretações sempre parciais e interessadas e somos impulsionados, de forma obrigatória, para uma explicitação dos pontos de vista adotados no estudo de determinado tema. Há, de fato, diversas opções epistemológicas, a depender dos instrumentos enfatizados para a compreensão e interpretação dos vestígios pré-históricos. Desde o surgimento da disciplina - Pré-História - a preposição "pré", usual nas linguas românicas e no inglês e similar em alemão (vor = anterior), tem caracterizado uma especificidade em relação ao conhecimento das sociedades com escrita, tomada a História como narrativa de e sobre as sociedades com registros escritos. ${ }^{1}$ Enquanto a História podia tentar descrever o passado wie es eigentlich gewesen (como propriamente aconteceu), para usar a expressão de Leopold Von Ranke, em 1823, ${ }^{2}$ a Pré-História voltava-se, ab initio, para a teoria social, em especial o evolucionismo em suas múltiplas manifestações, desde Lewis Morgan, passando por Vere Gordon Childe, para chegar aos nossos contemporâneos Robert Carneiro e Stephen Shennan. Outros preferiram haurir modelos interpretativos no culturalismo ou no estruturalismo, mas, em todos os casos, fez-se uso de interpretações antropológicas, no sentido lato, para procurar colocar as evidências em certa lógica.

Um aspecto antropológico de particular ressonância para o estudo dos vestígios materiais consiste no caráter narrativo, semiótico, comunicativo, da vida em sociedade. ${ }^{3}$

\footnotetext{
${ }^{1}$ Cf. FUNARI, P. P. A.; JONES, S.; HALL, M. (Org.). Introduction: archaeology in history. In:Historical Archaeology, Back from the edge. Londres: Routledge, 1999. p. 1-20.

${ }^{2}$ Cf. FUNARI, P. P. A. Antigüidade Clássica: A História e a cultura a partir dos documentos. 2. ed. Campinas: Editora da Unicamp, 2003; FUNARI, P. P. A.; SILVA, G. J. Teoria da História 1a. reimpressão 2010. 1. ed. São Paulo: Brasiliense, 2010.

${ }^{3}$ Cf. FUnARI, P. P. A. Lingüística e Arqueologia. DELTA. Documentação de Estudos em Linguística Teórica e Aplicada (PUCSP. Impresso), São Paulo, v. 15, n. 1, p. 161-176, 1999.
} 
A Semiótica tem se mostrado fecunda para o estudo do passado mais remoto, ao procurar entender a comunicação em situações para as quais temos muito pouca informação além da evidência material. A comunicação por meio de sons caracteriza a espécie humana, embora haja divergências sobre a sua emergência em algum momento específico do passado. Para diversos pré-historiadores, os Neandertais nunca desenvolveram essa capacidade, à diferença da nossa espécie, o que seria decisivo para a perpetuação dos seres humanos ${ }^{4}$ e demonstra a importância crucial da comunicação para a compreensão da humanidade. Embora não tenhamos acesso à fala dos paleolíticos, restaram-nos testemunhos eloquentes e numerosos da comunicação por meio de imagens e objetos. O desenvolvimento da Semiótica, como ciência dedica à comunicação não verbal, ${ }^{5}$ nas últimas décadas, tem sido da maior relevância para as propostas interpretativas da Pré-História em geral e do Paleolítico em particular. Como ciência dedica ao semeion, o sinal, ela tem contribuído para uma interpretação mais ampla e centrada naquilo que caracteriza o ser humano, sua capacidade de comunicar.

Em seguida, nessa mesma perspectiva antropológica, a Pré-História tem buscado explorar aspectos relevantes da experiência humana nem sempre levados em devida conta, tanto por preconceitos, como por fobias e receios. Dois aspectos, nesse sentido, saltam aos olhos: a espiritualidade e a sexualidade. Ambos os termos são modernos e, com tais definições, por certo, não existiam no Paleolítico. Contudo, forças que escapam à compreensão humana estão no cerne das preocupações humanas até os dias de hoje e, tanto mais, no passado mais recuado. Da mesma forma, a reprodução, com suas matrizes biológicas e instintivas, mas sempre revestida de aspectos simbólicos e culturais, nunca esteve muito distante das preocupações humanas. Basta lembrar a vinculação da Páscoa com o ciclo da morte e da vida, da

${ }^{4}$ Esse argumento está bem desenvolvido nos estudos de Clive Gamble, como em Origins and Revolutions, Human identity in earliest prehistory. Cambridge: Cambridge University Press, 2007.

${ }^{5}$ Cf. LAGOPOULOS, A. P. Subjectivism, postmodernism, and social space. In: Semiotica, 2011, 129-183.

156 Revista de História Regional 16(1): 154-180, Verão, 2011 
fertilidade, do renascimento agrícola e animal, ou, em termos ainda mais gerais, da Primavera com esses significados, para nos conscientizarmos do papel da sexualidade e da reprodução na sociedade e na simbologia do Paleolítico.

Nesse sentido, este artigo busca articular os três aspectos antropológicos mencionados: Semiótica, sexualidade e espiritualidade (ou representação simbólica). Sabemos bem que as evidências pré-históricas são parcas e de interpretação dificil e parcial. Não pretendemos prover uma única e verdadeira leitura da cultura material, mas sim fornecer um quadro conceitual que possa ser proficuo e que permita ao leitor tecer suas próprias conjecturas.

\section{Vestigios e seus significados}

Muito se tem discutido sobre a possibilidade de que alguns vestígios encontrados nas cavernas sejam de ritos iniciáticos; mesmo mantendo uma postura cautelosa, há indícios fortes disso. Nesse grupo de representações encontram-se, além da cena do poço, os vestígios da gruta de Tuc d'Audoubert, em Ariège. Nela, foi descoberto um santuário a cerca de 700 metros da entrada, sendo que para se chegar até ele é necessário atravessar um rio profundo, após o qual há centenas de traços de pés humanos calcados na argila. Como aponta Leroi-Gourhan, ${ }^{6}$ as marcas juvenis estão situadas fora dos trajetos pisados pelos adultos, nas poças ou nas partes úmidas, o que prova uma frequência tanto de adultos quanto de jovens e crianças no santuário. Nele, vê-se moldado em argila, acima de um pequeno estrato e apoiado contra uma muralha vertical, um casal de bisões. Segundo Mauduit, "o macho está prestes a cobrir a fêmea. Desse lugar

\footnotetext{
${ }^{6}$ Leroi-Gouhran descarta a ideia de ritual em seu texto, afirmando que a presença das pegadas de jovens e crianças não serve como testemunho, apenas indicaria a liberdade natural dessas, que gostam de pular em poças. Sem dúvida as crianças gostam de brincar na água, mas nos parece pouco razoável supor que elas tenham sido levadas até o mais profundo de uma caverna, através de passagens escuras e dificilimas, tendo que atravessar um rio subterrâneo, apenas para que brincassem em poças de água. LEROI-GOURHAN, A. Les religions de la préhistoire-paléolithique. 3. ed. Paris: PUF, 1970. p. 124.
} 
privilegiado partem em leque as impressões dos passos de cinco a seis jovens até o local onde estão reproduzidos outros tantos falos". ${ }^{7}$ A dificuldade de acesso ao local, a presença de vestígios de animais esculpidos e "feridos" com azagaias, o casal de bisões e os falos compõem um conjunto recorrente e que parece sim estabelecer um rito, no qual o falo, os animais e as armas são a tônica. Da mesma forma, nesses conjuntos pode-se descortinar uma narrativa (mítica) elementar que coloca no centro tensivo o homem e suas relações com o mundo natural. Narrativa marcada espacialmente pelos percursos escolhidos no interior das cavernas, na decoração: escolha dos animais, das cores utilizadas, dos métodos de pintura; e a presença do humano, quer seja nas perfurações feitas a partir das azagaias, nas pegadas deixadas no solo, ou na figura humana esquemática que contrasta com o requinte das imagens animais.

As pinturas de Altamira são outro exemplo, elas se encontram em um espaço de reduzidas dimensões: o teto desce para o fundo indo de uma altura de dois metros a pouco mais de um. Foi preciso escavar o solo para facilitar o acesso de pesquisadores e visitantes. Ou ainda as representações nas grutas de Mouthe (Dordonha), na qual a zona ornamentada começa a 93 metros da entrada, e de Niaux (Ariège), a 800 metros. Na maioria das vezes, as obras se encontram nos locais mais imprevistos. Em Montespan (Haute-Garonne) só se pode alcançar o local com as pinturas após atravessar um rio subterrâneo e gelado, sendo que a temperatura gira em torno de $12^{\circ}$, o que indica um espaço para cerimônias rituais de iniciação, pois não se justifica a dificuldade no acesso a não ser pela intenção simbólica. As primeiras obras de arte nesse sítio se encontram a 120 metros da entrada e prosseguem até o túnel final. ${ }^{8}$ Para ter acesso a elas é necessário mergulhar no rio e fazer essa travessia sob a água. Além do

\footnotetext{
${ }^{7}$ MAUDUIT, J. A. Quarenta mil anos de arte moderna. Tradução Pierre Santos e Jorge A. R. R. Alves. Belo Horizonte: Itatiaia, 1959. p. 134-5.

8 Informações retiradas de BÉGOUEN, M. M; CASTERET, N. La Caverne de Montespan (Haute-Garonne). Revìe de Antropologique. Disponivel em : <http:// 195.220.134.232/numerisation/tires-a-part-www-nb/0000005395408. pdf>. Acesso em: 24 out. 2010 e MAUDUIT, op cit, p. 134-5.
}

158 Revista de História Regional 16(1): 154-180, Verão, 2011 
frio, da necessidade de se saber nadar, a escuridão é outro ponto que dificulta o acesso à galeria "seca", onde se encontram as pinturas. A questão de serem essas cavernas santuários é corroborada, portanto, pelo difícil acesso e pela obra aí realizada.

Outros exemplos significativos são os animais esculpidos em argila e a "caçada" de Montespan. Nessa, um urso sem cabeça teria sido encontrado

[...] com um crânio de ursinho entre as patas da frente, tendo por cima uma pele fresca com a cabeça aderente; teria sido massacrado em efígie, a golpes de azagaia. $\mathrm{O}$ teto muito baixo, determina que os golpes foram dados de perto. Este é o décimo animal conhecido no fundo de uma gruta e está ferido como os ursos gravados de Trois-Frères, é acéfalo como os dois ursos no teto da gruta de Ekaïn, em Guipuzcoa. Em uma galeria separada, tão baixa, que é necessário rastejar até lá, encontra-se uma "caçada" em que se observa, ao longo de vários metros: os admiráveis quartos dianteiros de um cavalo acompanhados de uma nuvem de orificios e de dois traços verticais, o esboço de um cavalo assinalado com alguns traços verticais e alguns orificios, tendo igualmente ao lado uma nuvem de orificios, um terceiro animal com uma nuvem de orificios que lhe cobre o corpo, ultrapassando-o largamente para frente e, finalmente, uma série de traços verticais. $\mathrm{O}$ estado de conservação é tal que se pode estudar a direção de todos os impactos: trata-se não de uma caçada simulada, mas de um conjunto simbólico (em relação evidente com a caça) executado deitado sobre o lado, arrastando-se progressivamente e executando simultaneamente os animais, os pontos e os bastonetes. ${ }^{9}$

O pesquisador é bastante cauteloso, mas é impossivel não atentar para o fato de que todas as dificuldades na elaboração desse quadro possuem um valor simbólico, sobretudo quando a gruta tem um valor nitidamente feminino e o chifre/falo/flecha valor masculino, como ele próprio comprova ao analisar as variantes de signos masculinos e femininos

${ }^{9}$ LEROI-GOUHRAN, op. cit, 1990 , p. $124-5$ 
em sua obra. Os signos a são todos masculinos e remetem ora diretamente ao falo, ora à flecha e aos chifres. ${ }^{10}$ As gravuras do Divertículo dos Felinos de Lascaux (Figura 1) ${ }^{11}$ corroboram essa perspectiva. Localizado entre a Nave e o Abside, compreende um corredor estreito de aproximadamente 20 metros; no final do Abside encontra-se a cena do poço.

Figura 1 - Gravuras do Divertículo dos Felinos - Lascaux http://www.grands-sites-archeologiques.culture.fr

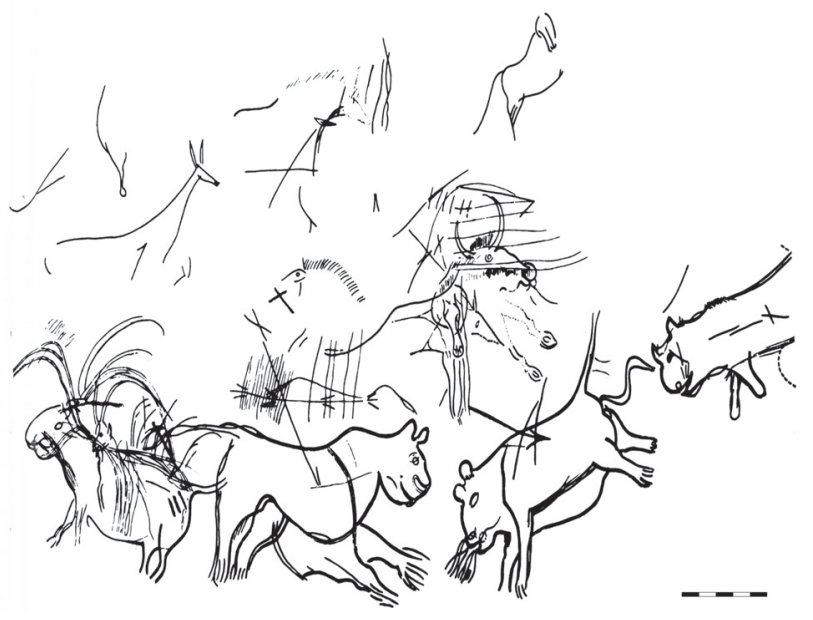

Figura 2 - Detalhe do Divertículo dos Felinos

\footnotetext{
${ }^{10}$ A descrição feita dessas cenas por Leroi-Gouhran sempre indica a presença de traços verticais, ou bastonetes à frente dos animais atingidos em efigie, podendo conotar talvez uma barreira (armadilha?) ou mesmo a chuva/fecundação, como na cabeça de Combarelles, analisada por nós em outro estudo, pois a chuva está intimamente ligada à fartura.

11 Imagens retiradas de <http://www.grands-sites-archeologiques.culture.fr> Acesso em 24 de out. de 2010.
} 
Dentre as gravuras do divertículo, cercado por uma pro-

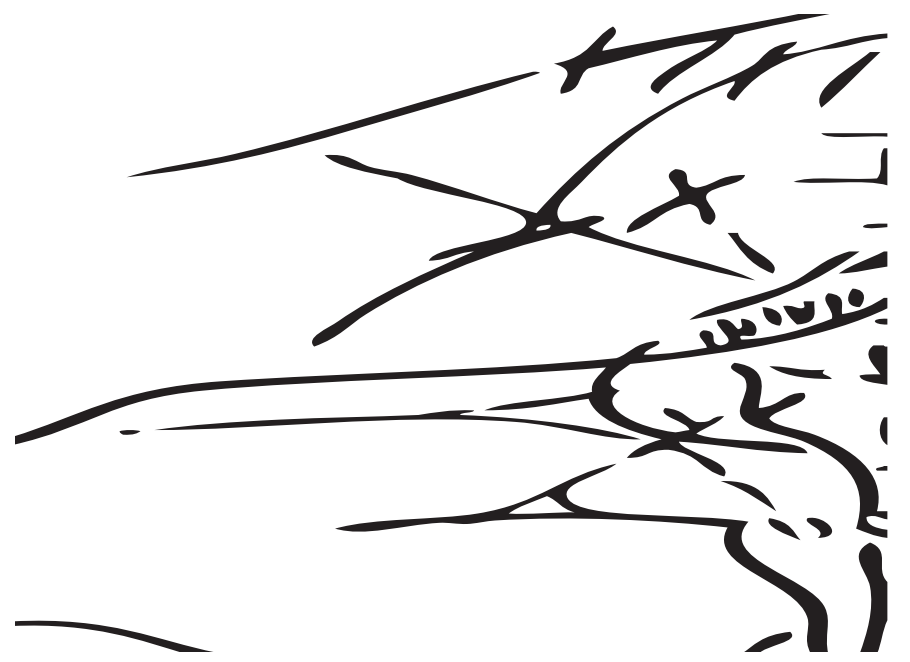

fusão de imagens animais, muitos feridos por signos masculinos (setas), encontra-se um falo/arma/flecha (Figura 2). A imagem, diminuta no conjunto, é formada pela parte inferior do tronco de um homem, com as pernas indicadas por linhas retas paralelas, mas sem indicação de pés ou joelho; o falo, aparentemente em semiereção, tem definido o saco escrotal que é cingido por dois arcos de circulo, talvez a virilha, talvez uma chaga/vulva. O homem/falo está sobreposto ao touro e a um animal não identificado, abaixo, e igualmente centrado, dois felinos parecem se confrontar, ambos feridos por flechas. Há uma sobreposição de traços na composição dos felinos que os assimila a suínos, talvez javalis, sobretudo o quarto traseiro do felino da esquerda. O conjunto estabelece uma triangulação bastante interessante: no vértice superior o falo, encimado pelos chifres do touro, e o quarto traseiro de cada felino nos vértices laterais. A supremacia do falo/chifre evidencia-se diante da caça ao felino/javali.

A cena toda é uma cena de caça e, embora as setas possuam as mais diversas origens, a presença do falo quase no centro do painel é relevante, assim como os falos presentes na gruta de Tuc d'Audoubert e do bastão gravado acima 
da cabeça do urso de Montespan, no teto da gruta. ${ }^{12}$ Trata-se de uma recorrência excessiva de signos para ser desprezada ou considerada acidental, fortuita, sobretudo quando se observa a intencionalidade na disposição dos elementos na representação dessas cenas.

\section{Ritos de Morte}

A inumação dos cadáveres entre os Neandertais já foi confirmada, em vários sítios europeus foram encontrados corpos enterrados em fossa, Chapelle-aux-Saints - Corrèze, ou em túmulos constituídos de montículo, La Ferrassie - Dordonha. Nesses casos, a ligação estabelecida entre a terra/caverna/montanha, o útero e um possivel renascimento do defunto é sugerida e posteriormente será atestada em culturas cuja religião já está desenvolvida. ${ }^{13}$ Contudo, a ligação estabelecida entre o morto, a terra e os chifres ainda é pouco aclarada. Segundo Leroi-Gouhran, "em Techik-Tach, no Turquestão, tornou-se clássica a sepultura de uma criança rodeada por cinco cabeças de cabrito-montês"; outra sepultura, datada do Paleolítico Médio, em "Qafseh, Israel, foi descoberta contendo um indivíduo que conservou sobre as mãos uma armação de gamo" ${ }^{14}$. Tanto o cabrito quanto o gamo possuem longos chifres/armação; o fato de se enterrar o morto junto com esses indica a necessidade de prover o cadáver de uma "arma" ou defesa para a outra vida, mas, sobretudo, possibilitar um veículo de fecundação da terra/ mãe para que a "nova semente" germine. O corpo/semente é enterrado no útero/ventre da terra; o morto, tal qual o homem e os consortes da terra/deusa mãe, deve ser portador

\footnotetext{
${ }^{12}$ MAUDUIT, op. cit., p. 135.

${ }^{13}$ Nas sepulturas do Paleolítico Superior, dos homo sapiens, observa-se já uma reincidência em pormenores que permite afirmar a existência de ritos mortuários nos quais a ideia de renascimento do morto é flagrada, sobretudo, pela posição "fetal", ou de flexão forçada - joelhos contra o queixo - na qual o corpo foi enterrado. (LEROI-GOUHRAN, op.cit., 1970, p.67).
}

${ }^{14}$ LEROI-GOUHRAN, op.cit., p.63 
de força, ferocidade e virilidade para poder transpor esse ciclo, como é retratado na cena do poço. ${ }^{15}$

O uso de adornos, como colares, pingentes ou redes, feitos a partir de conchas também é uma constante e está ligado à simbologia da vulva/terra. Diversos cadáveres foram encontrados portando esses objetos, segundo Leroi-Gouhran,

[...] um grande número [desses adornos] é constituído por conchas de littorina ou de espécies com forma mais ou menos esferóide, que podem ter evocado os caninos de veado. Existe, em todo caso, uma grande semelhança na forma entre os caninos de veado, as littorinas e numerosas contas de osso ou marfim que podem ter sido imitações de uns e de outros. ${ }^{16}$ Existem igualmente numerosos exemplares de $c y$ preas ou cauris, fósseis ou contemporâneas dos paleolíticos; no que diz respeito à cypreas, parece bastante provável que lhe tivessem atribuído o sentido, que permanece comum até os nossos dias, de simbolo sexual feminino. Isto é tanto mais verossímil quanto as representações femininas estilizadas da arte parietal e certos pingentes de osso, evocam o mesmo simbolo, numa forma muito próxima. ${ }^{17}$

A ligação das formas esferóides com o feminino já foi abordada, ${ }^{18}$ já o uso das littorinas e das cypreas na ornamentação dos mortos reforçam a constatação de que o homem paleolítico tinha o desejo de induzir ou possibilitar um renascimento ao morto através de práticas/ritos funerários e objetos investidos de valores mítico-mágicos, no caso, conchas de formas vulvares associadas a formas fálicas ou cobertas por pigmentação vermelha em algumas sepulturas.

${ }^{15}$ Em outro artigo, MARQUETTI, F.R. E FUNARI, P.P.A. Os Feiticeiros e a Cena do Poço: Ensaio sobre a religiosidade no Paleolítico, ainda a ser publicado pela Alétheia - Revista de estudos sobre Antigüidade e Medievo $\mathrm{n}^{\circ} 7$, tratamos especificamente da análise dessa cena.

${ }^{16}$ Nota-se uma aproximação aqui entre os objetos naturais e manufaturados, que ultrapassa o simples adorno, uma vez que tanto as conchas quanto os bastões, falos, estão investidos de valores sexuais.

${ }^{17}$ LEROI-GOUHRAN, op.cit, 1970, p. 76.

${ }^{18}$ Cf.: MARQUeTti, F. R. Da sedução e outros perigos. O Mito da Deusa Mãe. São Paulo: EDUNESP, 2011. cap. 1. No prelo. 
O percurso submerso necessário para a entrada em diversos desses locais reforça, por sua vez, a ideia de morte/ renascimento dos possiveis ritos, que seriam mediados pelo útero/caverna e pelo rio subterrâneo/líquido amniótico. O iniciado deveria transpor por duas vezes esse rio, ao entrar para a iniciação, morte e purificação, e ao sair, renascido, renovado, do útero da mãe terra. Essa possibilidade confirmaria a visão já atestada da morte como forma embrionária para a outra vida, representada pela inumação em pose fetal no período Paleolítico e em períodos posteriores dentro de cerâmicas de bojo arredondado.

\section{As cores e os ritos}

A arte parietal apresenta diversos estilos e maneiras de utilizar as cores. O seu uso, embora condicionado pelo material e técnica de que dispunha o homem no Paleolítico e Neolitico, pode ser analisado sob o prisma de uma intencionalidade artística e/ou semissimbólica, uma vez que as escolhas feitas demonstram o desejo de priorizar, dar relevo a determinadas partes dos corpos representados, bem como o de conotar um sentido.

A intencionalidade de indicar algo mais que a simples representação mimética da natureza pode ser sentida já na escolha da área a ser trabalhada, no uso das saliências naturais das paredes dos abrigos para retratar determinadas imagens, indicando uma proposta consciente, além de uma observação acurada do espaço a ser decorado. Em sua totalidade, as pinturas parietais encontram-se nas paredes e tetos mais profundos e de dificil acesso das cavernas, muitas vezes obrigando a passagem de rios subterrâneos e gargantas estreitas, nas quais é necessário rastejar e cujo diâmetro da abertura é diminuto; uma vez vencidas as dificuldades de acesso, essas cavernas apresentam salas amplas, ou capelas, repletas de imagens e composições que se sobrepõem; à luz das tochas ou fogueiras, parcial e oscilante, revelam-se imagens expressionistas que parecem envolver o homem 
num vórtice semissimbólico, que o arrasta ora para as profundezas do útero da terra/mãe, ora para fora.

Para executá-las, o homem paleolítico dispunha de algumas cores, do buril, instrumento de pedra que lhe permitia esculpir e gravar, e de seus dedos para traçar figuras na argila e modelar estátuas. As cores eram o preto, fornecido pelo carvão e o dióxido de manganês, o branco e o ocre vermelho. O ocre vermelho tem matizes variados, indo do amarelo ao vermelho, e por vezes o violeta. Era usado como lápis ou aplicado com a mão ou pincel. Segundo os estudiosos, essas tonalidades, colhidas nas vizinhanças, eram cuidadosamente levadas para os locais de moradia. Foram encontrados vários quilos dessas na gruta das Rochas (Indre) e na de Eyzies (Dordonha).

É possivel avaliar, pelos traços que ainda hoje as distinguem, o quanto essas cores realçavam as obras de arte móvel. O suporte era em geral pedras lisas ou alguns acidentes rochosos nos quais os volumes lembravam o objeto retratado. Sobre eles o homem traçava seus esboços e pode-se observar que em algumas regiões a mesma área foi utilizada várias vezes, os traçados se sobrepõem e, em alguns casos, se "complementam", transformando a obra primeira. Em algumas ocasiões, a cor era empregada para arrematar um desenho, como o provam as análises de obras parietais.

Ao recorrer às teorias da arte para tentar compreender as obras do Paleolítico e Neolítico, nota-se que o jogo entre os contrates de claro e escuro é uma constante, sobretudo no que toca ao uso do preto e do branco associados ao vermelho/ocre. Essas três cores amplamente usadas pelo homem pré-histórico apresentam um "padrão" de uso, com forte domínio do preto enquanto limite das formas preenchidas pelos tons de vermelho ou do branco em certos casos. Segundo Paul Klee: ${ }^{19}$

O dinamismo ótico descansa em uma progressão ou em uma digressão relativa à quantidade e qualidade da energia sucessivamente desprendida. Trata-se de obter um movimento visivel de fluxo e refluxo mediante a luta entre o claro e o

${ }^{19}$ KLEE, P. Theorie de 1'art Moderne. Genéve: Gonthier, 1971. cap. 8-I. 
escuro, que implica em um enérgico recurso dos extremos. A força do torneio supõe, por sinal, que os pólos opostos branco e preto - afirmem sua presença; oferecendo toda sua tensão ao jogo das forças que contrastam na escala dos matizes tonais.

O movimento do claro ao escuro e do escuro ao claro; subindo e descendo com a variação do tempo. ${ }^{20} \mathrm{O}$ branco é o estado dado; o agente (temporal) é o preto, e o inverso.

A ação deve ser a exceção e não a regra. A ação deve destacar-se sobre o fundo de um estado dado. Se desejo operar sobre tons claros, o estado dado deverá constituir um fundo escuro. Se desejo operar em profundidade, suponho imediatamente estados em tons claros.

\section{O preto e a definição de um limite}

No caso do grande touro negro de Lascaux, a forma do animal é revelada pelo contorno em negro, o que conota uma ação, um tempo que rompe o contínuo, o estado dado. Neste contexto de contínuo/natureza versus tempo/ação, o touro/macho como signo da morte, em oposição ao contínuo da vida, caverna/fêmea, é reforçado por esse limite. Somado a isso, o único elemento distintivo no interior do conjunto touro são as pintas ao redor do olho, que formam um círculo, indicando, dessa forma, outra quebra de continuidade. Essa quebra leva à representação não de um touro negro, como o denominaram os arqueólogos, mas sim de um touro "branco", cuja silueta se destaca do contínuo: parede da caverna.

\footnotetext{
${ }^{20}$ A noção de tempo colocada por Paul Klee para a pintura se firma na ideia de que qualquer superficie monocromática pode estabelecer um antes e um depois (ideia narrativa e, portanto, temporal) quando se aplica sobre ela um agente de contraste (traço, ponto, figura, entre outros). Ao se romper a homogeneidade, cria-se a fratura e o tempo, a Semiótica explora igualmente esse postulado. Cf.: ASSIS SILVA, I. Figurativização e metamorfose. $O$ mito de Narciso. São Paulo: EDUNESP, 1995; FLOCH, Jean-Marie. Petites Mythologies de l'oeil et de l'esprit. Pour une sémiotique plastique. Amsterdam: Hadès-benjamins, 1985 ; GREIMAS, A. J. Des dieux et des hommes. Paris: PUF, 1985, entre outros.
}

166 Revista de História Regional 16(1): 154-180, Verão, 2011 
O artista, ao mesmo tempo em que retrata o macho/morte sobre o ventre/caverna, também "retira" deste continuo/ útero/vida o animal - belo touro branco com algumas pintas formando um círculo ao redor dos olhos -, simbolo solar que gerará inúmeros descendentes míticos ao longo de toda a história humana.

A atração pelo ocre/vermelho, em contraste com o preto, marca a ação desejada pelo pintor pré-histórico e a intenção de valorizar uma massa quente que não só indica a força pujante do animal retratado, mas também a esfera na qual simbolicamente ele se insere, como ocorre com o bisão de Altamira.

A escolha de determinadas paredes das cavernas ou de acidentes rochosos como "fundo" (ou estado dado) para esta pintura também revela muito sobre o significado intentado pelo artista. Como ocorre na gruta Chauvet-Pont-d'Arc, França, ${ }^{21}$ no Pendente do Feiticeiro (Figura 3), no qual se observa o uso intencional do pendente, semelhante às ancas de uma mulher, ou ao delta púbico, e localizado no centro da sala do fundo, para ser ornado com a parte inferior de uma Vênus sobposta à cabeça de um "homem-bisão", o Feiticeiro.

A imagem, realizada unicamente em preto, encontra-se sobre a parte baixa do pendente calcário de cor ocre que desce do teto da gruta, terminando em ponta a uma altura de 1,10 metros do solo. Ao lado deste pendente, encontram-se diversas imagens de bisões, rinocerontes, felinos e um cavalo. Segundo a teoria de Leroi-Gourhan, ${ }^{22}$ as representações das grutas seguem um padrão, em pares opositivos complementares, ficando o cavalo associado à fêmea e o bisão ao macho. Sob essa perspectiva, é interessante notar que há apenas uma imagem parcial de fêmea, a vênus/vulva, e um cavalo, enquanto que os signos masculinos estão em maior número: homem-bisão, bisões, felinos e rinocerontes. Lembrando que a caverna é um signo eminentemente feminino para o homem pré-histórico, a representação no ponto mais

${ }^{21}$ Cf.: Les Grands Sites Archèologiques. Disponivel em: http://www.grandssites-archeologiques.culture.fr Acesso em 24 de out. de 2010.

${ }^{22}$ LEROI-GOURHAN, op.cit., 1990, p. 81-126 
profundo da gruta de uma vênus/vulva sobposta à cabeça/ cornos / falo de um homem-bisão indica a intenção de marcar a hierogamia entre a Deusa Mãe e seu consorte. ${ }^{23}$ A superfície ocre do fundo, um estado dado, destaca a ação em preto, ou, em uma leitura mais acurada, a base/fundo feminino da gruta é vista como um contínuo temporal (natureza), marcado e/ou rompido pela ação do homem, manipulação das forças sobrenaturais ou semissimbólicas pela união/representação do Feiticeiro sobre a vênus/caverna/Deusa Mãe.

Por outro lado, encontra-se igualmente a representação de uma oposição entre vida e morte, que leva ao renascimento, vista aqui como o de toda a natureza, um ciclo, e não apenas do iniciado, como na cena do poço com a presença do cavalo e do rinoceronte. ${ }^{24} \mathrm{O}$ negro sobre ocre é uma sobremodalização dos elementos retratados: masculino sobre feminino, uma vez que a terra ocre é mimetizada para o feminino e a vida, o negro do carvão está associado ao masculino/fogo/ morte.

${ }^{23}$ A maioria das representações de hierogamias se dá na parte mais profunda das grutas, segundo nosso levantamento.

${ }^{24}$ Cavalo vs. rinoceronte : : (sol) nascente vs. (sol) poente : : vida vs. morte $=$ renascimento.

168 Revista de História Regional 16(1): 154-180, Verão, 2011 
Figura 3 - Vênus e Feiticeiro. Gruta Chauvet-Pont-d'Arc, França. ${ }^{25}$

http://www.culture.gouv.fr/culture/arcnat/chauvet/en/ e INORA Lettre Internationale d'Information sur 1'Art Rupestre - $n^{\circ} 29-2001$

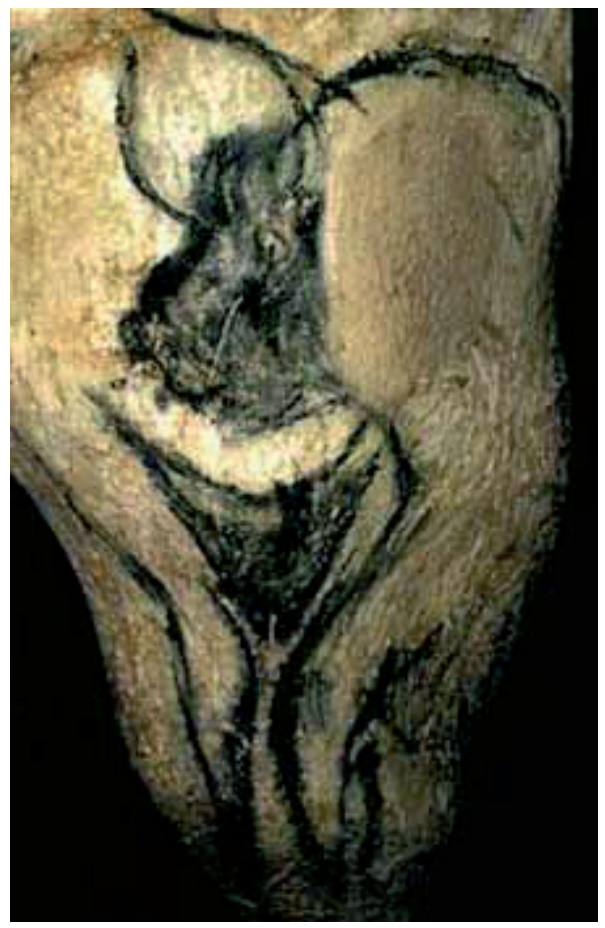

Ainda citando Paul Klee, existe para o ocidental um cânon que recupera, mesmo que esvaziados de seus valores semissimbólicos, toda uma sintaxe no uso das cores e sua localização na composição. Há, segundo o autor, uma:

Dimensão tonal: a dimensão "acima-abaixo" - lugar onde começa o esclarecimento. Muito acima o sol-luz; muito abaixo a noite.

${ }^{25}$ Imagem retirada de http://www.culture.gouv.fr/culture/arcnat/chauvet/en/ e INORA Lettre Internationale d'Information sur 1'Art Rupestre - n²9 2001 
Dimensão calórica (cor). A dimensão "direita-esquerda" é o local do princípio de temperatura. Na direita o sol-calor; na esquerda o frio. Se a dimensão tonal acrescenta a si uma ação cromática, nosso esquema se enriquece com a dimensão dos contrastes de temperatura. A conjugação das duas dimensões concede também duas dimensões ao movimento e contra-movimento. ${ }^{26}$

Como se observa, o homem pré-histórico usava, com exceção do azul (dificil de ser retirado da natureza), as cores fundamentais, sendo que sua disposição nas composições pouco ou nada se afasta da apontada por Klee. O jogo entre os contrastes de temperatura é a tônica das pinturas rupestres, o caminho da composição pictórica tem seu início com os homens pré-históricos e, no decorrer dos milênios, vai sedimentando, tornando pragmático o que era mítico-mágico, ou, em outras palavras, vai referencializando um conceito/ motivo mítico.

No caso da cena do pendente, o conjunto aponta para a valorização do baixo, associado à terra/gruta/vênus. Quanto à dimensão calórica, o pendente ocupa o coração da sala e associa duas cores básicas e opostas, ou seja, o ocre e o negro, o feminino e o masculino em um jogo de contrastes. É importante ressaltar que a representação feita aqui é a da hierogamia, não do feminino simplesmente. Esse já está implícito em toda a gruta, por isso o uso do preto para o conjunto, que delineia as duas imagens, que são contidas na cor ocre, exceção dos pontos chaves, o delta público e a cabeça do bisão. No conjunto da sala, o uso do preto sobre o ocre indica o estágio final deste ciclo, a morte e o princípio da renovação pela hierogamia/cópula do Feiticeiro com a vênus. Observa-se, assim, que a descida ao útero da terra, inumação, tem sua equivalência na cópula, uma vez que ambos ligam a morte e a vida. Percorrer os caminhos uterinos das cavernas e adorná-los com imagens pujantes (ou mesmo contemplá-lo) era, sim, uma ação simbólica, um rito que marcava a morte do indivíduo e seu renascimento, prova de força, coragem, virilidade. A presença de vestígios femininos,

${ }^{26}$ KLEE, P., op. cit., cap. 8-II

170 Revista de História Regional 16(1): 154-180, Verão, 2011 
mãos e pés, no interior das cavernas não contradiz a ideia de um rito viril, sobretudo por ser a mulher um simile da própria gruta e, portanto, um possivel auxilio nessa passagem.

As novas técnicas de utensílios, como a invenção do buril de pedra, permitiram ao homem criar sua obra. Os documentos deixados no Auraciano pelos primeiros Homo sapiens, criadores da arte, são raros, porém irrefutáveis.

\section{O ocre-vermelho}

O fato de a mão suja de tinta ou carvão deixar sua marca numa parede foi para o homem primitivo uma revelação. Às vezes, era a mão suja de tinta que ele pousava na parede, outras - mais frequentemente -, colocava a mão na parede e aplicava a tinta ao redor, deixando aparecer assim uma imagem negativa.

Segundo Mauduit, ${ }^{27}$ as noções técnicas adquiridas já haviam mostrado o poder da mão, instrumento universal, apropriado a todos os usos, da qual a imagem foi pelo homem paleolítico dotada do mesmo poder, prolongando de certa forma sua própria personalidade e possuindo no espírito o poder do corpo humano completo. Na maioria das vezes, essas mãos se localizam no fundo das grutas, e esse fato faz supor que os lugares onde são encontradas foram testemunhas de ritos. Esses locais se encontram na Espanha em Cantábria, Altamira e Castilho; nas grutas de Combarelles Font de Gaume, em Dordonha; na Cabrerets em Lot, na gruta de Trois-Frères em Ariège, e na gruta de Gargas, para citar apenas alguns dos principais locais. Na gruta de Castilho, elas estão associadas a pontos vermelhos ou pretos. ${ }^{28}$

O uso da cor vermelha preponderante nas impressões das mãos conota o valor atribuído a elas, poder mágico de vida, de criação/representação; são uma metonimia do fazer humano e da vida. O vermelho está ligado à vida, ao sangue

${ }^{27}$ MAUDUIT, op. cit., passim.

${ }^{28}$ Os pontos são um símbolo masculino, segundo Leroi-Gouhran (op. cit., 91). 
e ao fogo, elementos essenciais à vida do homem primitivo, sobretudo se pensarmos que, para ele, mesmo o sangue derramado possuía toda uma ambivalência: era indício de morte e de vida, o sangue do animal morto era ao mesmo tempo morte para a natureza e vida para o grupo; tal qual o fogo que representava um elemento sobrenatural/divino (vindo do céu - os raios que atingiam as árvores), fonte de calor; de defesa; de luz e, portanto, de sociabilidade, como também causador de morte.

Signo de posse e poder mágico, a imagem da mão será em seguida retomada pela maioria dos povos, que lhe modificarão o desenho e o símbolo para adaptá-la à sua própria sensibilidade. Sob a feição mais simples, ela poderá tomar o aspecto de uma impressão ou de uma imagem negativa, tal como as encontradas nas grutas franco-cantábricas no princípio do Auraciano. Nessa mesma área, ela aparecerá ainda - porém mais tarde e estilizada - sob a forma de um ancinho de cinco dentes, quando será retratada quase que exclusivamente pela cor preta. É interessante notar a transformação da mão em ancinho, marcando bem a função desses: a de juntar, arrebanhar algo. Essa "abstração" ou transformação prefigura o sentido mítico-mágico das mãos nas cavernas, o de posse, o de colher para si e para seu grupo bens essenciais, como os alimentos (vegetais e/ou animais). Outra questão interessante é a de que a mão, natural, é substituída por um artefato cultural - ancinho -, indicando uma transformação semelhante à estabelecida entre o chifre/falo e a flecha. Como esses, o ancinho fere a terra com seus dentes; o uso do preto em oposição ao vermelho anterior reforça a transformação sêmica de vida para morte, uma vez que o ancinho encontra-se agora na esfera do cultural - colheita.

Outro uso significativo da cor vermelha está na gruta de Portal, em Ariège, uma saliência da parede, semelhante a um falo ereto, foi cingida de vermelho e sua imagem completada com a silhueta de um personagem humano. 
Figura 4 - Homem/falo, gruta do Portal (Ariège) http://www.hominides.com/html/art/art_parietal3.php

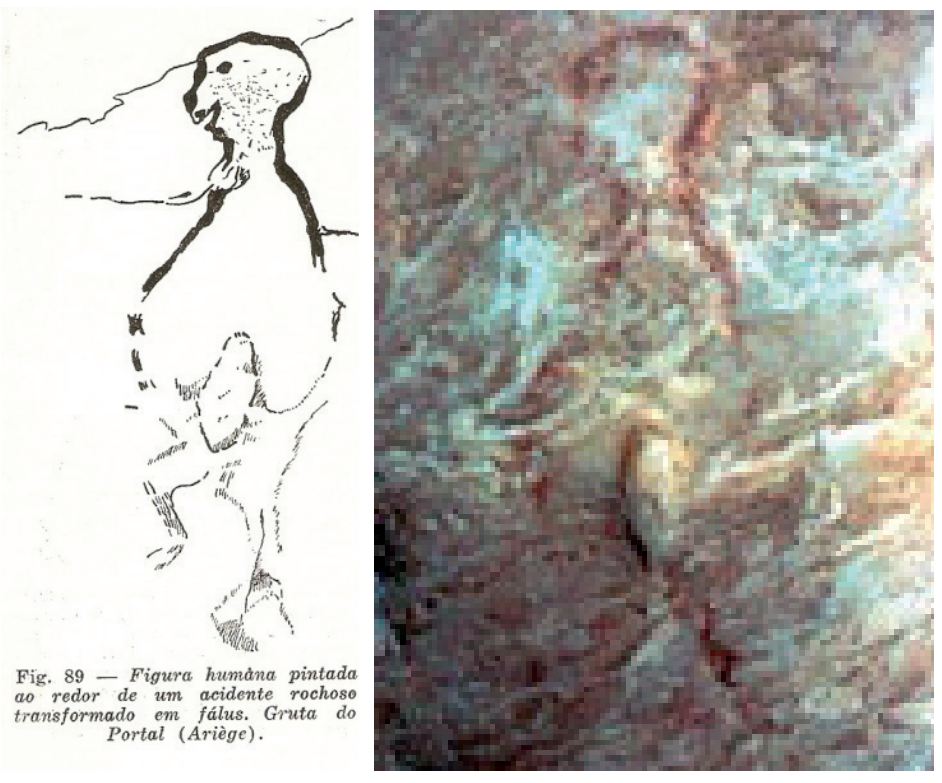

A cor vermelha utilizada na impressão das mãos ou de seu negativo, assim como o falo cingido, destacado pela cor, indica mais do que um simples uso. A escolha do vermelho na representação de alguns animais, como o bisão de Altamira, e no contorno de algumas imagens, como na Vênus de Laussel, demonstra uma escolha intencional tanto para a pintura/escultura do objeto quanto para a cor escolhida. O bisão de Altamira tem destacadas principalmente a região da cabeça, do dorso e a região do osso sacro com o vermelho, áreas que indicam força e virilidade. Na Vênus de Laussel, o chifre, que ela traz na mão direita, além da indicação dos 13 meses lunares, sugere estar repleto de "sangue", pois há traços de pigmentação vermelha na abertura desse e em torno da cabeça e do corpo da Vênus, bem como sobre os seios e o 
ventre. ${ }^{29} \mathrm{O}$ escultor indica, assim, que a deusa foi banhada pelo vermelho/sangue/fogo vindo do chifre, ou cornucópia, como preferem denominar alguns pesquisadores, ou emerge desse.

Atentando para a leitura feita até o momento em nossa pesquisa de que o falo e o chifre se equivalem, o uso da cor vermelha saindo da cornucópia sustentada pela Vênus, indica: em primeiro lugar, a relação da Deusa Mãe paleolítica com o sangue "derramado" 30 de um cornudo (o uso do chifre não é acidental) e a necessidade do sangue/fogo/sol para fecundá-la; em segundo, reforça a equivalência chifre/falo. Embora os pesquisadores afirmem que no período dos caçadores coletores ainda não se conhecida a relação existente entre cópula e nascimentos, há fortes indícios em nossa pesquisa de que eles detinham esse conhecimento. A analogia entre o sangue e o falo/esperma, como fonte de vida, se daria ainda por meio de sua associação à chuva e ao raio (fogo celeste).

A presença da cor vermelha circundando o falo da Figura 4 reforça a leitura, sobretudo quando a representação

${ }^{29}$ Ao realçar os seios e o ventre da Vênus de Laussel com a cor vermelha, vê-se uma sobreposição de semas contextuais: os depreendidos das formas arredondadas e curvas dos seios e do ventre - transformados no universo mítico-mágico em conotação de vida -; e os depreendidos do cromatismo vermelho, ligado ao sangue e ao fogo: em ambos o valor vida/morte está imbricado. O sangue como princípio da vida e limite da morte (ao ser derramado significa morte; matricial e uterino, o sangue menstrual é promessa de vida e, quando expelido, torna-se motivo de tabu e interdição em quase todas as culturas orientais e ocidentais). $\mathrm{O}$ fogo, como o sangue, traz a ambivalência do benéfico - aquece e protege - e do perigo destruidor. $\mathrm{O}$ vermelho, como as formas femininas, representa um fascínio e um temor - um universo mágico e desconhecido, já prenunciado nas representações mais arcaicas, como no Camarim das vulvas, pintadas em vermelho intenso, formam um grupo de seis; sua forma é circular e a fenda vulvular indicada por um traço ou por um ângulo agudo que rompe o círculo; duas delas são completadas por um traço paralelo ao circulo e aberto em sua parte superior, sugerindo um esboço do corpo feminino. Contemporânea à Vênus de Laussel, a Vênus V de Vestonice também apresenta traços de coloração vermelha sobre o ventre.

30 Os vestígios de cor vermelha em outras esculturas, como na Vênus de Willendorf, permite essa leitura. Cf.: MARQUETTI, op.cit. cap. 2.

174 Revista de História Regional 16(1): 154-180, Verão, 2011 
foi feita a partir do próprio. O falo é o elemento central dessa representação, o restante foi composto a partir dele. Isso demonstra o seu poder mítico-mágico, que já se inscreve na dicotomia de vida (calor/fogo) e morte (frio/escuro). A prática de ofertar falos às deusas da fertilidade e da guerra perdurou até o século V, como é o caso do seixo de Antibes, em formato de falo e cuja inscrição reforça a imagem. O seixo foi oferecido a uma Afrodite guerreira e hermafrodita. ${ }^{31}$

A relação do vermelho com o sangue e com o fogo persistiu até a Grécia do período clássico. Ares, Hefesto, Zeus e outros deuses ligados à guerra e cuja virilidade é atestada estão ligados ao fogo (lava, raio) e ao manuseio dos metais / armas, visto assim como elemento de destruição, a ideia de abrasar pelo desejo ou pelo fogo e sua condição funesta é bem atestada no mito de Sírius. ${ }^{32}$

\section{O vermelho e o renascimento}

A cor vermelha também foi bastante encontrada em sepulturas, quer sob a forma de pó com o qual os corpos estavam polvilhados, quer sob a forma de bastonetes dispostos perto da cabeça ou nas proximidades da mão. Em certos casos, uma reserva de pó vermelho estava depositada em frascos, como o formado por um osso oco coberto com uma tampa, datado do Magdaleniano Superior, objeto que acompanhava uma jovem morta em sua vida subterrânea.

Ao compreender os mecanismos de morte e nascimento, o homem estabeleceu uma analogia entre o defunto e o feto. Como a morte por derramamento de sangue deveria ser a mais frequente, as imagens do corpo banhado de sangue do morto e a do feto, que entra na vida do mesmo modo, foram sobrepostas e fundiram-se numa montagem metonímica; o

${ }^{31}$ BAZIN, H. Galet inscrit d'Antibes. Offrande phallique a Aphodite. Etude d'Archéologie Religieuse Grèco-Orientale. Paris: Ernest Leroux, Editeur, 1885.

${ }^{32}$ Cf.: TRIOMPHE, R. Le lion, la vierge et le miel. Paris: Les Belles Lettres, 1989, passim. 
feto nasce do útero feminino, ao passo que o morto volta ao útero da terra para, depois de um período, renascer; se o sangue envolve o feto, a cor vermelha o substituirá no morto. Dessa forma, inundava-se o cadáver de vermelho, cor do sangue, encontrado em todas as sepulturas do Paleolítico Superior. Certas partes do corpo, consideradas importantes, eram protegidas com pequenas pedras erguidas e enterravase junto ao morto objeto de valor para esse e/ou o grupo. Encontrou-se, por exemplo, em Grimaldi, enterrado na gruta de Cavaillon, próxima a Menton, o corpo de um homem de grande estatura repousando sobre o lado esquerdo, as pernas ligeiramente curvadas. O crânio e o peito estavam abrigados sob uma série de pequenas pedras. A cabeça estava ornada com uma rede composta de centenas de pequeninas conchas mediterrâneas entre as quais se encontravam dentes de cervídeos. Braceletes de conchas enfeitavam igualmente os braços e as pernas. Duas lâminas de sílex achavam-se aplicadas a seu occipúcio (parte inferoposterior da cabeça), em uma espécie de sulco intencionalmente aberto diante da fossa nasal se reconheciam as cavidades com cor vermelha, simbolo da vida. ${ }^{33}$

Há vários indícios do poder do homem enterrado nessa sepultura, o que se evidencia pelo cuidado na inumação e pelos adornos nela contidos. As conchas são um símile da vulva e, portanto, da Deusa Mãe; ${ }^{34}$ a rede que protege e ornamenta a cabeça do homem está repleta de pequenas conchas, entremeadas com dentes de cervídeos; o dente pode ser usado como um substituto do falo/chifre, sobretudo aqui, quando os dentes são de animais portadores de chifres. A mescla de conchas e dentes na rede indicaria um entrelaçar de vida/morte e a hierogamia da Deusa com seu consorte, que remete à ideia de produção de vida, renascimento, confirmado pelo sulco diante das fossas nasais - aspirar ao vermelho é aspirar vida, calor.

${ }^{33}$ Segundo Leroi-Gouhran (op. cit., 1970, p. 73), é comum a representação de animais com traços/linhas vermelhas que partem do focinho e são interpretados como a figuração da respiração. No caso humano, foi assimilado ao sopro de vida. ${ }^{34}$ Cf.: MARQUETTI, op.cit. cap. 2. LEROI-GOURHAN, op. cit., 1990, p.73-78. 
De modo semelhante, as esculturas das vênus de Vestonice que foram encontradas num antigo acampamento de caçadores de mamutes retomam o motivo da Deusa e sua ligação com a vida e a morte. Elas foram encontradas entre os restos de uma habitação subterrânea e uma sepultura contendo a cor vermelha ritual.

O ciclo de vida, morte e renascimento, reconhecido pelos homens do período como natural, já que observado na terra/mãe, é transferido para o grupamento humano e, assim como as pinturas parietais, visavam garantir a fecundidade, a reprodução e a renovação da natureza, a ornamentação dos mortos, sobretudo com o vermelho, garantiria o retorno à vida.

Leroi-Gourhan ${ }^{35}$ contesta a crença na inumação como rito comum a todos os homens paleolíticos, atribuindo a um acaso os corpos encontrados dentro das cavernas, pois, segundo o pesquisador, os paleoliticos inumavam fora de seu habitat, ao ar livre. As supostas sepulturas surgiriam acidentalmente em alguma gruta desocupada e próxima, em função da erosão e deposições. No entanto, ele próprio enumera os problemas de seu posicionamento, apontando para alguns casos bem documentados de inumação. Dentre eles, uma sepultura em Shanidar, no Iraque, na qual foi encontrado um esqueleto escondido sob um amontoado de pedras, que repousava sobre uma camada de matéria orgânica vegetal. A análise dos polens fossilizados revelou que ela comportava os restos de numerosas flores que devem ter sido colocadas sobre o corpo antes da sua cobertura. A conservação dos polens e o seu agrupamento atestavam a introdução de flores e não de polens trazidos pelo vento ou pelos animais.

O uso das flores para cobrir um cadáver a ser inumado é bastante significativo, sobretudo quando retomado o sentido primeiro da flor, órgão de reprodução das espécies vegetais. Colher uma flor é privar a natureza e o homem, por consequência, de frutos, de novas plantas, da manutenção da vida, ação tabu em culturas primitivas e que tem seus

${ }^{35}$ LEROI-GOURHAN, op. cit., 1970, p.60-69. 
ecos em diversos mitos gregos, como o de Perséfone. Ofertar, portanto, flores ao morto é proporcionar um gérmen de vida a esse, em detrimento do grupo, o que pode indicar a importância do morto para o mesmo.

Em Qafseh, Israel, foi descoberta, ainda segundo Leroi-Gourhan, uma sepultura do Paleolitico Médio, contendo um indivíduo inumado que conservou sobre as mãos uma armação de gamo. Nela, como no caso da sepultura encontrada em Arene Candide na Itália, na qual o esqueleto estava acompanhado de quatro bastões de comando, pode-se observar a mesma protofigurativização para o chifre/bastão, símbolo de poder/força/virilidade, alternando-se entre o natural e o cultural.

Sobre o uso do ocre/vermelho nas sepulturas, o pesquisador ainda reluta, dizendo que em diversos sítios o solo se encontra a tal ponto impregnado de ocre que era natural que os restos aí encontrados contivessem vestígios dele. A leitura pragmática feita pelo pesquisador não deixa de ser correta, porém a adoção de sítios impregnados de ocre para a inumação é algo a ser considerado. O ato de cavar a sepultura em solo que permite envolver todo o defunto em ocre/vermelho/vida é significativo, implica a escolha de um local em detrimento de outro, portanto, intenção - sobretudo quando, em 16 desses casos, os corpos traziam numerosos objetos de adorno pessoal.

As sepulturas do Paleolítico Superior, dos homo sapiens, já apresentam um terreno mais seguro, segundo o pesquisador, ${ }^{36}$ pois são inúmeras escavadas em fossas e nas quais o corpo do morto foi polvilhado de ocre vermelho. Há uma especial atenção para o crânio quanto ao uso dessa pigmentação: em alguns locais, apenas a cabeça do morto foi colorida com o ocre. Ainda segundo Leroi-Gouhran, isso indicaria pouca quantidade do material para o uso. Contudo, é possivel pensar em outra relação, aproximando a cabeça do morto com a do feto, pois ela é a parte maior no conjunto desproporcionado que é o corpo do recém-nascido, sem falar

${ }^{36}$ LEROI-GOURHAN, op. cit., 1970, p.66.

178 Revista de História Regional 16(1): 154-180, Verão, 2011 
de sua inegável semelhança com a semente. A vista superior da face externa do crânio é idêntica à da semente ${ }^{37} \mathrm{e}$, como ela, o crânio possui uma carapaça, caixa craniana.

Ao que tudo indica, o ser humano do Paleolítico estabeleceu correlações muito mais sutis e requintadas do que até aqui se supôs, pois observa-se um jogo semissimbólico, portanto mítico, entre os elementos da natureza, o sexo, as representações encontradas nas cavernas e abrigos e a vida/ morte.

\section{Considerações finais}

Na modernidade, acostumamo-nos a separar esferas da sensibilidade humana em apartados estanques: reprodução, espiritualidade, sexo, morte, prazer, dor. Nem sempre foi assim. Na profundidade histórica da humanidade, encontramos aspectos dos sentidos que se separaram e que raras vezes se reencontram no nosso quotidiano moderno. Na antiguidade mais recuada, no Paleolítico, nossos antepassados mais distantes produziram imagens que se tornaram, para nós, misteriosas, segundo a etimologia grega do termo: algo fechado, que não está evidente. Imagens fechadas não porque escondidas, mas porque nos faltam as ferramentas de leitura dos seus antigos autores. Resta-nos colocá-las em quadros conceituais mais amplos, que relacionem questões universais e permanentes - como a reprodução e o prazer - com situações sociais concretas de uma era para sempre perdida e distante de nós. Neste artigo, propusemos leituras de algumas evidências que nos parecem adquirir sentido, à luz de algumas inquietações humanas básicas. O leitor julgará o fundamento das nossas propostas.

\footnotetext{
${ }^{37}$ Conferir imagens e informações em: http://www.auladeanatomia.com/osteologia/ craniocomoumtodo.htm Acesso em 03 de jan. de 2011.
} 


\section{Agradecimentos}

Agradecemos a Clive Gamble e Alexandros Phaidon Lagopoulos. Mencionamos, ainda, o apoio institucional do CNPq, FAPESP, Unicamp e Unesp. A responsabilidade pelas ideias restringe-se aos autores.

Resumo: O presente artigo aborda os vestígios encontrados nas cavernas do período Paleolítico e sua possivel ligação com ritos iniciáticos. A análise é pautada por uma leitura semiótica, na qual se busca a apreensão de uma estrutura narrativa mínima para as representações imagéticas. Nessas representações, se descortina todo um universo ligado à caça, ao chifre e ao falo que estabelece um conjunto complementar com o feminino/caverna, representando uma oposição entre vida e morte. Para tanto, foram analisados elementos constitutivos das cenas representadas, como localização geográfica, cores utilizadas e intencionalidade na representação.

Palavras-chave: Cena. Narrativa. Ritos. Cor.

Abstract: The present paper analyzes evidences found on caves of the Paleolithic Era and their possible relation to initiation rites. The analysis is oriented by a semiotic reading, which seeks to perceive a minimal narrative structure within the pictorial representations. These representations unveil a whole universe related to hunting and to horn and phallic references, which establishes a complementary relation with the feminine/cavern and represents an opposition between life and death. For the purposes of this article, elements of the represented scenes were analyzed, such as geographical localization, the colors that were used, and the intention of the representations.

Keywords: Representation. Narrative. Rites. Color.

Artigo recebido para publicação em 24/04/2011

Artigo aprovado para publicação em 06/06/2011

180 Revista de História Regional 16(1): 154-180, Verão, 2011 